\title{
A Review of the Extrapulmonary Manifestations of the 2019 Novel Coronavirus Disease (COVID-19)
}

\author{
Paul Toluwatope Okediji ${ }^{\text {* }}$ (1), Ademola Samuel Ojo ${ }^{2}$ (), Ayotemide Priscilla Akin-Onitolo ${ }^{3}$ (C)
}

${ }^{1}$ Synberg Research \& Analytics, Abuja, NIGERIA

${ }^{2}$ St. George's University School of Medicine, St. George's, GRENADA

${ }^{3}$ Solina Center for International Development and Research, Abuja, NIGERIA

*Corresponding Author: email@affiliation.com

Citation: Okediji PT, Ojo AS, Akin-Onitolo AP. A Review of the Extrapulmonary Manifestations of the 2019 Novel Coronavirus Disease (COVID-19). Journal of Contemporary Studies in Epidemiology and Public Health. 2020;1(2):ep20008. https://doi.org/10.30935/jconseph/8499

\begin{abstract}
Background: Since the onset of the 2019 novel coronavirus disease (COVID-19), many reports have presented the disease as a respiratory disease, thereby limiting diagnosis to presentations with respiratory symptoms. This review critically analyzes and consolidates published literature describing extrapulmonary features of COVID-19.

Methods: Recently published full-text literature on the extrapulmonary manifestations of COVID-19 was reviewed. The studies reviewed focused on the cardiovascular, gastrointestinal, nervous, hematopoietic, genitourinary, and musculoskeletal systems; and ocular, otorhinolaryngological, and cutaneous symptoms.

Results: A total of 28 original articles were selected and analyzed. The most common extrapulmonary manifestations were acute cardiac injury (7.2-19.7\%), arrhythmia (16.7\%), and shock (8.7\%) in the cardiovascular system; anorexia (83.8\%), liver abnormality (14.8-37.2\%), diarrhea (3.8-29.3\%), abdominal pain (0.4-12.0\%), nausea $(9.5 \%)$, and vomiting $(0.8-5.0 \%)$ in the gastrointestinal system; acute cerebrovascular disease and loss of consciousness (36.4\%) in the nervous system; lymphopenia (40.0\%-64.0), leukocytosis (14.3-23.4\%), anemia (15.0\%), thrombocytopenia $(7.0 \%)$, elevated D-dimer $(42.0 \%)$, and prolonged prothrombin time $(2.1-6.0 \%)$ in the hematopoietic system; and proteinuria (43.9-62.7\%), hematuria (26.7\%), elevated urea (27.1\%) and creatinine (18.6\%), and acute kidney injury (3.6-5.1\%) in the urinary system. Others include sore throat (28.6\%), erythematous rash (15.9\%), arthralgia/myalgia (14.8\%), widespread urticaria (3.4\%), and singular reports of acute myopericarditis, acute lymphocytic myocarditis, meningitis, viral encephalitis, testicular pain, anosmia, and acute conjunctivitis.

Conclusion: COVID-19 affects every organ-system and can cause extrapulmonary symptoms with or without respiratory symptoms. A high index of suspicion is required to help healthcare providers achieve early diagnosis, prompt treatment, and reduce the chances of spreading the disease within the community.

Keywords: COVID-19, SARS-CoV-2, extrapulmonary symptoms, cardiovascular, gastrointestinal

Received: 30 Jun. 2020 • Accepted: 31 Jul. 2020
\end{abstract}

\section{INTRODUCTION}

The emergence of the 2019 novel coronavirus disease (COVID-19) in late 2019 sparked a global public health crisis which countries around the world have been grappling with. With an incidence of almost two million cases of the disease within the first four months of the first reported cases, COVID-19 has established itself as one of the world's worst infectious disease outbreaks since the Spanish flu of the 1900s. The chronology of the disease commences in Wuhan, Hubei Province, China, where initial reports originated of people admitted to hospitals with severe pneumonia-like illness caused by the Severe Acute Respiratory Syndrome Coronavirus 2 (SARS-CoV-2; formerly referred to as the 2019 novel Coronavirus - 2019-nCoV) [1]. Between December 18, 2019 and January 30, 2020; the numbers of those affected had risen to 7734 in China, and 90 novel cases were reported in several countries including Japan, Cambodia, Malaysia, Thailand, Taiwan, Republic of Korea, United States, United Arab Emirates, Canada, France, and Germany [2]. Within the first few months of onset, millions of cases had been confirmed across 210 countries and territories worldwide [3]. The disease's case fatality rate has been determined to be $3.7 \%$ even though this varies from region to region due to factors such as testing rates, quality of supportive care, immunogenetics, population demographics, and discrepancies between actual and official reports of number of mortalities $[4,5]$.

Given the increasing numbers of individuals affected by COVID-19 and its ramifications on public health, researchers have responded with an increasing amount of published evidence describing the origin, epidemiology, transmission, clinical features, and treatment options for COVID-19. Many of the published studies and case reports describe COVID-19 as a respiratory syndrome ranging from mild upper 
respiratory illness to acute respiratory distress and severe interstitial pneumonia $[4,6,7]$. This is further bolstered by evidence indicating significant similarities between the symptoms of COVID-19 and those of previous epidemics caused by human coronaviruses (Severe Acute Respiratory Syndrome and Middle East Respiratory Syndrome) such as fever, dry cough, dyspnea, sore throat, and the radiological finding of bilateral ground-glass opacities $[2,7,8]$. However, new case reports have begun to emerge indicating that COVID-19 is not a purely pulmonary disease but one that has extrapulmonary manifestations across all the major organ systems. Many of these novel publications throw more light on how SARS-CoV-2 directly affects other organs through its cytopathic effects and/or indirectly through a multi-organ dysfunction arising from immune response to the virus. This review critically analyzes all relevant published literature describing extrapulmonary features of COVID-19 and consolidates the findings. It is expected that this report will provide clear guidance to clinicians, epidemiologists, and other health care professionals involved in rapidly identifying COVID-19 cases and providing the necessary care.

\section{METHODOLOGY}

This study is based on a review of published scientific literature describing pulmonary and extrapulmonary manifestations of COVID19. The authors conducted a search on PubMed for COVID-19 related articles using relevant keywords: COVID-19, manifestation, cardiac, gastrointestinal, nervous, hematologic, ocular, ear, nose, throat, genitourinary, musculoskeletal or any combination of these search terms. Additional relevant articles were identified from the reference list of already selected papers using a snowballing method. All articles were screened and included in the review if they were written in English and full-text original articles in the form of case reports, case series, and observational studies. Editorials, reports, and other nonscientific commentaries were excluded from the review. Duplicate articles were also eliminated. Following careful selection via independent and joint review of selected papers, 28 scientific papers were included and analyzed for the purpose of this review. A description of selected studies is presented in Table 1.

Table 1. Summary of included studies describing extrapulmonary manifestations of COVID-19

\begin{tabular}{|c|c|c|c|c|c|}
\hline System & Author [reference] & Country & Study type & $\begin{array}{l}\text { Number } \\
\text { of cases }\end{array}$ & Features \\
\hline \multirow[t]{4}{*}{$\begin{array}{l}\text { Cardiovascular } \\
\text { system }\end{array}$} & Shi, Qin, \& Shen [9] & Wuhan, China & $\begin{array}{l}\text { Prospective cohort } \\
\text { study }\end{array}$ & 416 & Acute cardiac injury (19.7\%) \\
\hline & Inciardi, Lupi, \& Zaccone [10] & Italy & Case report & 1 & Acute myopericarditis with systolic dysfunction (100.0\%) \\
\hline & Sala, Peretto, \& Gramegna [11] & Milan, Italy & Case report & 1 & Acute lymphocytic myocarditis (100.0\%) \\
\hline & Wang, $\mathrm{Hu}, \mathrm{Hu}$, et al. [12] & Wuhan, China & Case series & 138 & Acute cardiac injury (7.2\%), arrhythmia (16.7\%), and shock (8.7\%) \\
\hline \multirow[t]{6}{*}{$\begin{array}{l}\text { Gastrointestinal } \\
\text { system }\end{array}$} & $\begin{array}{l}\text { Holshue, DeBolt, Lindquist, et } \\
\text { al. [13] }\end{array}$ & United States & Case report & 1 & Nausea, vomiting, diarrhea and abdominal discomfort (100.0\%) \\
\hline & Guan, Ni, Hu, et al. [14] & China & Retrospective study & 1,099 & Diarrhea (3.8\%) and vomiting (5.0\%) \\
\hline & Chen, Chen, Deng, et al. [15] & China & Retrospective study & 42 & Diarrhea (16.7\%), abdominal pain (12.0\%), and nausea (9.5\%) \\
\hline & Pan, Mu, Yang, et al. [16] & Hubei, China & Cross-sectional study & 204 & $\begin{array}{l}\text { Anorexia }(83.8 \%) \text {, vomiting }(0.8 \%) \text {, diarrhea }(29.3 \%) \text {, and } \\
\text { abdominal pain }(0.4 \%)\end{array}$ \\
\hline & Cai, Huang, Ou, et al. [17] & Shenzhen, China & Retrospective study & 298 & Liver injury (14.8\%) \\
\hline & Fan, Chen, Li, et al. [18] & Shanghai, China & Retrospective study & 148 & Abnormal liver function $(37.2 \%)$ \\
\hline \multirow[t]{3}{*}{ Nervous system } & Mao, Wang, Chen, et al. [19] & Wuhan, China & Retrospective study & 214 & Acute cerebrovascular disease and loss of consciousness (36.4\%) \\
\hline & Li, Huang, \& Guo [20] & Beijing, China & Case report & 1 & Meningitis (100.0\%) \\
\hline & $\begin{array}{l}\text { Moriguchi, Harii, Goto, et al. } \\
\text { [21] }\end{array}$ & Yamanashi, Japan & Case report & 1 & Viral encephalitis (100.0\%) \\
\hline \multirow{4}{*}{$\begin{array}{l}\text { Hematopoietic } \\
\text { system }\end{array}$} & Chen, Wu, \& Guo [22] & Tongji, China & Retrospective study & 21 & Leukocytosis (14.3\%) and lymphopenia (42.9\%) \\
\hline & Ruan, Yang, Wang, et al. [23] & Wuhan, China & Retrospective study & 150 & Lymphopenia, leukocytosis, and anemia \\
\hline & Zhou, Yu, \& Du [24] & Wuhan, China & $\begin{array}{l}\text { Retrospective cohort } \\
\text { study }\end{array}$ & 191 & $\begin{array}{l}\text { Lymphopenia }(40.0 \%) \text {, leukocytosis }(21.0 \%) \text {, anemia }(15.0 \%) \text {, } \\
\text { thrombocytopenia }(7.0 \%) \text {, elevated D-dimer }(42.0 \%) \text {, and } \\
\text { prolonged prothrombin time }(6.0 \%)\end{array}$ \\
\hline & Wu, Chen, \& Cai [25] & Wuhan, China & $\begin{array}{l}\text { Retrospective cohort } \\
\text { study }\end{array}$ & 201 & $\begin{array}{l}\text { Lymphocytopenia }(64.0 \%) \text {, leukocytosis }(23.4 \%) \text {, and prolonged } \\
\text { prothrombin time }(2.1 \%)\end{array}$ \\
\hline \multirow[t]{5}{*}{$\begin{array}{l}\text { Genitourinary } \\
\text { system }\end{array}$} & Cheng, Luo, \& Wang [26] & China & $\begin{array}{l}\text { Prospective cohort } \\
\text { study }\end{array}$ & 701 & $\begin{array}{l}\text { Proteinuria (43.9\%), hematuria (26.7\%), reduced eGFR }<60 \\
\mathrm{ml} / \mathrm{min} / 1.73 \mathrm{~m}^{2}(13.1 \%) \text {, and acute kidney injury }(5.1 \%)\end{array}$ \\
\hline & Li, Wu, Guo, et al. [27] & China & Retrospective study & 59 & $\begin{array}{l}\text { Proteinuria }(62.7 \%) \text {, elevated creatinine }(18.6 \%) \text {, and elevated } \\
\text { urea }(27.1 \%)\end{array}$ \\
\hline & Wang, Li, Chen, et al. [28] & Wuhan, China & Retrospective study & 116 & Elevated urea and creatinine (10.8\%) \\
\hline & Wang, $\mathrm{Hu}, \mathrm{Hu}$, et al. [12] & Wuhan, China & Case series & 138 & Acute kidney injury (3.6\%) \\
\hline & Kim, Thomsen, Sell, et al. [29] & United States & Case report & 1 & Testicular pain (100.0\%) \\
\hline $\begin{array}{l}\text { Musculoskeletal } \\
\text { system }\end{array}$ & $\begin{array}{l}\text { World Health Organization } \\
{[30]}\end{array}$ & China & Retrospective study & 55,924 & Arthralgia/myalgia (14.8\%) \\
\hline \multirow[t]{2}{*}{$\begin{array}{l}\text { Ears, nose, } \\
\text { and throat }\end{array}$} & Kim, Chin, \& Kang [31] & South Korea & $\begin{array}{l}\text { Prospective cohort } \\
\text { study }\end{array}$ & 28 & Sore throat $(28.6 \%)$ \\
\hline & Gane, Kelly, \& Hopkins [32] & United Kingdom & Case report & 1 & Acute loss of smell (100.0\%) \\
\hline \multirow[t]{2}{*}{ Ocular } & Chen, Liu, \& Zhang [33] & Shenzhen, China & Case report & 1 & Bilateral acute conjunctivitis (100.0\%) \\
\hline & Lu, Liu, \& Jia [34] & Wuhan, China & Case report & 1 & Left acute conjunctivitis (100.0\%) \\
\hline \multirow[t]{2}{*}{ Cutaneous } & Recalcati [35] & Lombardi, Italy & Observational study & 88 & $\begin{array}{l}\text { Cutaneous manifestations (20.5\%), erythematous rash (15.9\%), } \\
\text { widespread urticaria (3.4\%), and chicken pox-like vesicles (1.1\%) }\end{array}$ \\
\hline & Zhang, Dong, Cao, et al. [36] & Wuhan, China & Retrospective study & 140 & Urticaria (1.4\%) \\
\hline
\end{tabular}




\section{PATHOGENESIS}

\section{Origin and Transmission of SARS-CoV-2}

The causative agent of COVID-19, SARS-CoV-2, has been classified as a beta-coronavirus and the seventh member of a family of human coronaviruses. The name "coronavirus" originated from the Latin word for crown, corona, as the presentation of the virus under an electron microscope is crown-like because of the tiny projections on the viral envelope. SARS-CoV-2 is a spherical, single-stranded, positive sense, RNA virus with its genome enclosed in a ball of matrix proteins [37]. Prior to the discovery of SARS-CoV-2, there had previously been six human-susceptible coronaviruses, four of which cause a mild respiratory illness often referred to as the common cold (229E and NL63 which are alpha-coronaviruses and HKU1 and OC43 which are beta-coronaviruses) [6]. The remaining two have been associated with more serious respiratory illnesses with high fatality rates - the Severe Acute Respiratory Syndrome coronavirus (SARS-CoV) and Middle East Respiratory Syndrome coronavirus (MERS-CoV) which are both beta-coronaviruses similar to SARS-CoV-2 [38]. The similarities between the genome sequences of SARS-CoV-2 and SARS-CoV and MERS-CoV are approximately $80 \%$ and $50 \%$ respectively suggesting similar origins of these beta-coronaviruses [39].

Based on the similarities between COVID-19 and SARS, there are hypotheses that bats are the animal reservoir of SARS-CoV-2 as there is no direct evidence linking bats with SARS-CoV-2. Analysis of the SARS-CoV-2 shows that there is a $96.2 \%$ similarity to a bat CoV RaTG13 [6]. While there is a sizable amount of ongoing research to trace the origin of SARS-CoV-2, there has also been interest in understanding how human-to-human transmission of the virus occurs. Nosocomial transmissions have been the basis of the spread of SARS and MERS. In COVID-19, the majority of the transmission has been from close contact of family members, friends, and acquaintances with symptomatic or asymptomatic carriers of the virus [40]. Human-tohuman transmission of the virus occurs primarily through inhalation of virus-laden droplets released via sneezing or coughing by an infected individual or direct contact [2]. The degree of reproducibility of COVID-19 is estimated to be 2.0 to 4.7 suggesting greater pandemic potential than SARS (1.7 to 1.9) and MERS $(<1)$ [41-43]. Also, the fact that the disease is contagious even during its latency period contributes to its ability to spread easily [44]. The disease's average incubation period is between 2 to 14 days, with an average of $4.8 \pm 2.6$ days $[6,43,45]$.

\section{Viral Structure and Proteins}

Genomic analysis of the SARS-CoV-2 has shown that the virus has as many as $29.9 \mathrm{~kb}$ base pairs which makes it one of the largest among all known RNA viruses $[37,46]$. Like other members of the coronavirus family, there are 14 open reading frames (ORFs) in the genome of SARS-CoV-2 encoding for 27 proteins: 15 of which are non-structural proteins necessary for successful replication of the virus and 12 structural proteins: spike (S), envelope (E), membrane (M), and nucleocapsid $(\mathrm{N})$ proteins, as well as eight accessory proteins that alter the host's immune response $[7,47,48]$. Since the first discovery of the virus in late 2019, multiple strains of the virus have emerged as a result of mutations in the viral genome. Zhang et al identified multiple genotypes of SARS-CoV-2 among COVID-19 patients from different provinces in China [49]. It is not yet clear how many genotypes of the virus exists among populations. Researchers have made attempts at classifying existing SARS-CoV-2 genotypes into two categories: the L type which is found in approximately $70 \%$ of COVID-19 patients and the S-type found in the remaining 30\% [50]. Preliminary evidence indicates that the L-type SARS-CoV-2 which is more prevalent and derived from the $\mathrm{S}$-type tends to be more contagious and aggressive, implying the need for the consideration of viral genotypes in designing interventions to prevent and control the disease [6].

\section{Viral Entry and Replication in Cells}

Among all the proteins produced by SARS-CoV-2, the spike (S) glycoprotein plays a significant role as it facilitates entry of the virus into target cells. The virus enters the cell by binding to cell receptors using its S glycoprotein which consists of two subunits - S1, which mediates cellular tropism, and S2, which facilitates fusion between the virus and the host's cell membrane [6]. The presence of the angiotensinconverting enzyme 2 (ACE2) receptor on the surfaces of cells in the lower respiratory tract is another critical factor necessary for viral entry. The exact process of cell membrane invagination and endocytosis following the binding of the virus' $\mathrm{S}$ glycoprotein to ACE2 receptor is not clear. Guo et al suggest that the S2 subunit of the $\mathrm{S}$ glycoprotein mediates fusion between the virus and the cell membrane which is followed by the release of the viral genome RNA into the cytoplasm of the host cell [6]. Upon entry, the uncoated RNA undergoes translation into two polyproteins (pp1a and pp1ab) and form a replicationtranscription complex (RTC) within its own tiny vesicle [51,52]. The RTC begins to replicate and synthesize additional sub-genomic RNAs that encode structural and accessory proteins that support the process of replication. Newly formed genomic RNAs with the help of mediating Golgi bodies, endoplasmic reticulum, E and N glycoproteins form multiple virion-loaded buds which merge with the plasma membrane to undergo exocytosis.

The interplay between the S glycoprotein and ACE2 receptor has been the subject of intense study due to its significance in enabling viral entry. Compared with the 2003 strain of the SARS-CoV, the S glycoprotein of SARS-CoV-2 binds 10 to 20 times more efficiently, although not as efficiently as the more pathogenic 2002 strain of SARS$\mathrm{CoV}[6,7]$. This binding efficiency has been attributed to six mutations that occurred on the RBD region of the S glycoprotein that interacts with ACE2 receptor [48]. At present, the 2002 strain of SARS-CoV is more pathogenic than SARS-CoV-2 as evidenced by the higher severity of illness caused by SARS relative to COVID-19. The fatality rate in SARS (9.5\%) is also higher than the current estimates of that of COVID19 (3.7\%) [4,53]. However, it has been predicted that should an additional single nucleotide mutation occur on the RBD of SARS-CoV2, viral-ACE2 receptor binding efficiency will increase leading to increased pathogenicity of SARS-CoV-2 and worsened prognosis of individuals with COVID-19 [54]

\section{Host Immune/inflammatory Response to SARS-CoV-2}

There is a dearth of evidence on the host's immune response to the presence of SARS-CoV-2 in the body. A number of researchers have described the role of pathogen-associated molecular patterns (PAMPs), pattern recognition receptors (PRRs) and toll-like receptors (TLRs) in mediating the immune response to coronaviruses. According to Frieman et al. [55], the activation of the immune system in response to invading viruses occurs via two major pathways: (i) detection of viruses in endosomal cell compartments by TLRs (especially TLR3, TLR7, TLR8, and TLR9), and (ii) detection of viral RNA in the cytoplasm by 
cytoplasmic caspase activation and recruitment domains (CARD) which comprises RNA helicases, retinoic-acid inducible gene I (RIG-I), and melanoma differentiation-associated gene 5 (MDA5). Either of these pathways can be triggered by interactions of each pathway's components with PAMPs which in the case of SARS-CoV-2 is the RNA of the virus as it invaginates into the cytoplasm. This results in the initiation of multiple downstream cascades leading to the activation of interferon regulatory factor 3 (IRF3) and transcription nuclear factor$\kappa \mathrm{B}(\mathrm{NF}-\kappa \mathrm{B})$ as well as the production of interferons and a wide variety of other proinflammatory cytokines [56].

Studies on COVID-19 patients have reported the upregulation of cytokines such as interleukin-1 (IL-1), IL-2, IL-4, IL-7, IL-10, IL-12, IL13, IL-17, granulocyte colony-stimulating factor (GCSF), hepatocyte growth factor (HGF), macrophage colony stimulating factor (MCSF), IFN- $\gamma$, and IFN- $\alpha[6,8,57]$. In essence, viral entry triggers a broad immune reaction which if not controlled can lead to immunopathology and undesirable outcomes. Liu et al described an inflammatory response in the lower respiratory tract as a result of immune response to COVID19, leading to significant lung injury [58]. Researchers have documented the major clinical features of COVID-19, with the most common being fever, dry cough, dyspnea, sore throat, and muscular soreness [59]. Also, many other studies have referred to COVID-19 as an "acute respiratory infectious disease" $[4,6,43]$. What is not yet clear is how the virus causes these symptoms - whether through a direct viremic effect or the effect of the myriad of cytokines released - and whether the effects are limited to just the respiratory system or extend to several other organ systems. This obscurity is due in part to confounding caused by the fact that a significant proportion of COVID19 patients have other comorbidities which influence the clinical characteristics they present with [12,13,59-61]. A more critical review of emerging evidence of extrapulmonary symptoms related to COVID19 may yield a lot more answers and throw more light on how the human body responds to SARS-CoV-2 and what the outcomes are

\section{EXTRAPULMONARY MANIFESTATIONS OF COVID-19}

\section{Cardiovascular System Involvement}

Cardiac affectation alone or in addition to respiratory failure is responsible for up to $40 \%$ of death in SARS-CoV-2 infection [23]. Cardiac manifestations can occur in the absence of pulmonary manifestations [10]. Myocardial injury has been reported in COVID-19 with manifestations of acute myocarditis, pericarditis, heart failure, shock and arrhythmia [10-12,62]. A report on 153 COVID-19 patients found acute cardiac injury, arrhythmia, and shock in $7.2 \%, 16.7 \%$, and $8.7 \%$ of cases respectively, and noted that myocardial injury increased the risk of mortality (Table 1) [9].

Different underlying mechanisms for cardiac injury have been proposed. These include cytokine storm resulting from hyperinflammation, hypoxemia induced cardiac injury and direct viralmediated myocardial damage [63-65]. Elevated inflammatory markers such as IL-2, IL-6, IL-7, interferon-gamma, tumor necrosis factor, ferritin, C-reactive protein and procalcitonin in COVID-19 support the presence of hyperinflammation [66,67]. Sala et al reported a case of acute myocardial inflammation with T-lymphocytic infiltration of the myocardium in the absence of SARS-CoV-2 genome, suggesting other mechanisms may contribute to myocardial injury in COVID-19 [11]
Additional supportive evidence for myocardial injury include elevated cardiac troponin I and T, NT-proBNP, creatinine kinase-MB and myoglobulin $[10,62,68]$. The presence of elevated myocardial injury biomarkers correlate with increased ICU admission, need for ventilator support and death [9,12]. Dobutamine, steroids, chloroquine, antivirals, and heart failure medications have been used in the treatment of acute myocarditis-related heart failure $[10,63]$

\section{Gastrointestinal System Involvement}

Human coronaviruses are known to affect the liver and gastrointestinal (GI) system [69,70]. The incidence of liver injury in COVID-19 ranges from $14.8 \%$ to $78 \%$ in the literature $[17,18]$. This is largely characterized by deranged levels of liver aminotransferases, bilirubin, and gamma-glutamyl transferase. Studies show that severe COVID-19 cases are more likely to develop liver injury and the extent of damage is also higher in cases with severe illness [70,71]. Although unclear, it is thought that the cytopathic effects of the virus in cholangiocytes, which have ACE2 receptors, indirectly leads to liver damage $[70,72]$. It is also suggested that the liver is affected by inflammatory cytokine storms associated with SARS-CoV-2 and druginduced injury [72]. There is need for further research to understand the pathogenesis of liver damage in COVID-19. In addition, clinicians must closely monitor liver function in COVID-19 patients and minimize exposure to potentially toxic drugs. There is insufficient evidence to demonstrate the relationship between COVID-19 and preexisting liver disease [70]. As such, there is need for more studies on this.

Similar to SARS and MERS that cause diarrhea in $20-25 \%$ of patients [73], COVID-19 cases demonstrate GI affectation. Observed symptoms include anorexia, diarrhea, vomiting and abdominal pain. The incidence range is estimated at $1.3-29.3 \%$ [16]. A cohort study of 1,099 patients in China put the prevalence of diarrhea and vomiting at $3.8 \%$ and $5.0 \%$ respectively, in addition to pulmonary symptoms [14]. Among 42 cases, $16.7 \%$ had diarrhea, $12.0 \%$ had abdominal pain, 9.5\% had nausea and $7.1 \%$ presented with vomiting [15]. The first case in the United States presented with GI symptoms [13]. While many COVID19 patients have accompanying GI symptoms, studies show that some patients have these symptoms first, and subsequently develop respiratory symptoms, while a smaller proportion of patients have only GI complaints. Among 204 Covid-19 cases in Hubei, China, 48.5\% of them presented primarily with GI complaints while $3.4 \%$ of the cases had no respiratory symptoms [74]. The actual prevalence of GI manifestations may be underestimated. Data culled from the Chinese national reporting system as at 20 February 2020 had no record of GI symptoms [75]. Notably, affected patients had more severe illness compared to those without, which could be related to delayed recognition and admission [72]. Clinicians need a higher index of suspicion when managing patients with GI complaints.

Gastrointestinal manifestations are often linked to the interaction between SARS-CoV-2 and ACE2, inflammation which may occur indirectly or as a result of antibiotic use, and gut flora affecting the respiratory tract through immune regulation [72]. SARs-CoV-2 has been detected in stool samples $[13,15,74]$. Across studies, cases with positive stool tests range from $29 \%$ to $67 \%$. In some patients, stool samples remained positive longer than respiratory samples [74]. SARSCoV-2 may remain detectable in stool samples for 1-12 days [74] and 6-10 days after negative respiratory samples [15]. The presence of the virus in stool samples is not directly related to the presence of GI 
symptoms [15,76] or severity of illness. This raises concerns about possible faeco-oral transmission from asymptomatic carriers. Current guidance recommends discharge after at least two consecutive negative respiratory samples collected one or more days apart [72,77]. However, this does not factor in continued viral shedding in stool samples observed in a significant proportion of cases. Currently, treatment is largely focused on symptomatic support [78]. Patients with liver injury are more likely to require ICU support [74].

\section{Nervous System Involvement}

Like SARS and MERS, nervous system affectation has been reported in COVID-19 patients. Among 214 COVID-19 cases studied retrospectively, $36.4 \%$ of them developed nervous system manifestations such as acute cerebrovascular disease and loss of consciousness, which were more prominent among those with severe disease [19]. However, there is insufficient evidence to specifically attribute these symptoms to SARS-CoV-2. Two definitive cases of meningitis [21] and viral encephalitis associated with SARS-CoV-2 have been reported in Japan and Beijing respectively [20]. It is thought that SARS-CoV-2 may gain access to the brain through direct spread across the cribriform plate or hematogenous spread. As the capillary endothelium expresses ACE2 inhibitors, viral particles in the blood may interact with the endothelial cells and breach the blood brain barrier. Rupture of the endothelium could lead to acute cerebrovascular events which can be fatal. The virus also replicates and causes damage to neuronal cells [79]. Authors have postulated that the severe inflammatory response and hypoxia associated with SARS-CoV-2 can cause damage to the brain $[80,81]$. It is not yet known if pre-existing conditions increase the risk of COVID-19 nervous system manifestations.

Although SARS patients have shown viral nucleic acid in cerebrospinal fluid (CSF), more conclusively, SARS-CoV-2 was detected in the CSF of the meningitis and encephalitis cases $[20,82]$. There are concerns that SARS-CoV-2 could remain latent in the nervous system and like Herpes Simplex virus, become reactivated in the future [83]. Details on when and how it might reappear are still unclear. Although the impact of SARS-CoV-2 on the nervous system is not fully understood, there is a need for prompt assessment of COVID19 patients with nervous system symptoms and a look out for cases that could, although rarely, show up with nervous system manifestations as the chief complaint.

\section{Hematopoietic System Involvement}

Leukocytosis and lymphopenia are common findings in COVID19. The spectrum of white blood cell count range from normal to leukocytosis in moderate to severe disease and this increase has been attributed to an elevated neutrophil count [22]. Lymphopenia due to low T-lymphocyte (CD4+ and CD8+) cells has been reported in all stages of the disease and has been linked with increased disease severity as well as mortality [23]. Possible mechanisms underlying lymphopenia include; direct viral-mediated destruction due to the presence of ACE2 on these cells, viral-induced lymphoid organs dysfunction and proinflammatory cytokine-induced lymphocytic apoptosis [84-86].

Mild anemia has been reported in COVID-19 [10] and 21 out of 28 patients with COVID-19 in a cohort study had anemia [87]. Although the exact mechanism of anemia is not clear, it may be due to the effect of pro-inflammatory cytokines in shortening the lifespan of red cells, and blunting the response of erythroid cells to erythropoietin [88].
Elevated D-dimer, thrombocytopenia, prolonged prothrombin and activated partial thromboplastin time suggestive of coagulopathy have been reported to correlate with a high risk of acute respiratory distress syndrome, multiple organ dysfunction, and death $[24,25,89]$.

\section{Genitourinary System Involvement}

Acute kidney injury has been reported in COVID-19 and its occurrence has been associated with increased mortality [26,90]. A prospective cohort study involving 701 COVID-19 patients show $43.9 \%, 26.7 \%$ and $13.1 \%$ had proteinuria, hematuria and estimated glomerular filtration rate under $60 \mathrm{ml} / \mathrm{min} / 1.73 \mathrm{~m}^{2}$, respectively [26] Furthermore, acute kidney injury was reported in $5.1 \%$ of the cases. Similar report by Li et al found proteinuria, hematuria, elevated urea and creatinine in 59\%, 44\%, 14\%, and $10 \%$ of admitted patients respectively [27]. Also, $10 \%$ of patients in another study had elevated serum creatinine or blood urea nitrogen [28]. Renal CT scan studies in patients with COVID-19 revealed hypodensities suggesting renal parenchyma inflammation and edema [26]. The proposed mechanisms of renal affectation in COVID-19 are a combination of direct virusmediated and cytokine-induced renal injury [90].

In addition to renal symptoms, Kim et al reported a case of testicular pain as a presenting symptom of COVID-19 [29]. Similar to renal tubular cells, ACE2 expression is found in the testis and may be responsible for testicular involvement [91]. A post-mortem study on SARS cases suggest that the disease led to orchitis with spermatogenetic dysfunction [92].

\section{Musculoskeletal System Involvement}

A report of 55,924 confirmed cases of COVID-19 by the World Health Organization show that $14.8 \%$ had arthralgia or myalgia [30]. This is similar to SARS in which $26.7 \%$ of cases reported joint pain [93]. Arthralgia is a common feature of viral infections and has been reported as an initial presentation of COVID-19 [30,94]. Joint manifestations are usually not associated with abnormal findings on magnetic resonance imaging [95]. It is possible that the arthralgia and myalgia in COVID19 are related to the wide circulation of pro-inflammatory cytokines, and the sensitization of nociceptors in muscles and joints by inflammatory mediators [96].

\section{Nose, Throat, and Ear Involvement}

The nose is a common route of SARS-CoV-2 entry into the body, and it is therefore a site of upper respiratory manifestations. Symptoms include sneezing, runny nose, nasal congestion, post nasal drip and acute loss of smell [97]. The loss of smell is a subtle symptom which could manifest early in the disease and could be the only symptom in seemingly asymptomatic individuals [32]. More so, acute loss of smell is a common feature of upper respiratory tract infections. The underlying mechanisms are mucosal inflammation and edema resulting in blockage of olfactory clefts, and virus-mediated olfactory epithelial destruction [98]. While the former typically improves within weeks, the latter could persist for years [99]. Pharmacotherapy involving the use of topical and oral steroids in addition to olfactory training has been dubbed the mainstay of treatment [98]. Sore throat due to viral pharyngitis is another common manifestation reported in up to $28.6 \%$ of COVID-19 cases [31]. It manifests with soreness, scratchiness, or irritation. Viral pharyngitis is associated with pharyngeal edema, redness and mild exudates [100]. Anecdotal reports from COVID-19 survivors suggest ear pain as a presentation of the disease. Ear pain is a common association of pharyngitis and can be caused by direct spread 
of infection from the pharynx to the middle ear through the pharyngotympanic tube [101].

\section{Eye Manifestations}

Chen et al reported bilateral conjunctivitis in a patient 13 days after the onset of systemic symptoms with a positive viral RNA in conjunctival swab [33]. An infectious disease expert developed conjunctivitis after visiting Wuhan several days before the onset of respiratory symptoms [34]. This raises the possibility of ocular involvement in COVID-19 as studies have shown that the presence of ACE2 may facilitate viral entry in the retina, retinal pigment epithelium [102], and conjunctival epithelia [103]. Features of viral conjunctivitis include red eye, tearing, discharge, itchiness, and crusting of eyelashes.

\section{Cutaneous Manifestations}

In a study of 88 patients in Italy, Recalcati reported 18 developed cutaneous manifestations affecting mainly the trunk, with erythematous rash, widespread urticarial and chickenpox-like vesicles occurring in fourteen, three, and one patient respectively [35]. Other authors have also reported skin rash with petechiae in a patient and suggested that skin lesions could manifest early in the disease [104]. Urticaria was reported in $1.4 \%$ of patients in a report on 140 cases of COVID-19 [36]. Although there is limited report on the cutaneous features of COVID-19, it is safe to assume that akin to other viral infections, skin manifestation is not uncommon.

\section{MANAGEMENT OF THE EXTRAPULMONARY MANIFESTATIONS OF COVID-19}

Extrapulmonary manifestations can occur in the absence of typical disease symptoms, as a result, a high index of suspicion is required for diagnosis. Making a diagnosis involve taking history as well as performing physical examination. History of contact should be sought in all suspected cases. Reverse transcriptase-polymerase chain reaction is required for the confirmation of COVID-19. Other laboratory investigations such as complete blood count, comprehensive metabolic panel, coagulation studies, imaging as well as other specialized tests could suggest the extent of the disease.

Treatment is aimed at the primary inciting agent as well as other underlying mechanisms of disease manifestation. Suggested potential therapies against the virus include antiviral agents such as viral RNA polymerase inhibitor (remdesivir) [105] and, protease inhibitors [106] (lopinavir, ritonavir). Cytokine storm resulting from hyperinflammation has been implicated in many extrapulmonary manifestation of the disease. Potential therapies directed at limiting the inflammatory response include the use of corticosteroids, chloroquine, hydroxychloroquine, as well as immunomodulatory agents like tocilizumab (IL-6 blocker) and anakinra (IL-1 blocker) [105,107]. Specialized care should be directed at specific organ dysfunctions.

\section{CONCLUSION}

This study has been able to establish that COVID-19 affects every organ-system in the human body and cause extrapulmonary symptoms with or without respiratory symptoms. While the disease continues to spread around the world at a fast pace, it is important for healthcare providers, epidemiologists, and other personnel involved in managing
COVID-19 cases and/or controlling disease spread to have a high index of suspicion. The understanding that COVID-19 often presents more "atypically" than is assumed will encourage more patients to present early and help healthcare providers achieve early diagnosis, prompt treatment, and reduced chances of spreading the disease within the community.

\section{REFERENCES}

1. Du Toit A. Outbreak of a novel coronavirus. Nat Rev Microbiol. 2020;18(3):123.

2. Rothan HA, Byrareddy SN. The epidemiology and pathogenesis of coronavirus disease (COVID-19) outbreak. J Autoimmun. 2020;109(February):102433. (doi: 10.1016/j.jaut.2020.102433).

3. World Health Organization. Coronavirus Disease 2019 (COVID19): Situation Report - 84. Vol 2019. 2020. Available at: https:// www.who.int/docs/default-source/coronaviruse/situationreports/20200413-sitrep-84-covid-19.pdf?sfvrsn=44f511ab_2

4. Rodriguez-Morales AJ, Cardona-Ospina JA, Gutiérrez-Ocampo E, et al. Clinical, laboratory and imaging features of COVID-19: A systematic review and meta-analysis. Travel Med Infect Dis. 2020;34:1-13. (doi: 10.1016/j.tmaid.2020.101623).

5. Battegay M, Kuehl R, Tschudin-Sutter S, Hirsch HH, Widmer AF, Neher RA. 2019-novel Coronavirus (2019-nCoV): estimating the case fatality rate-a word of caution. Swiss Med Wkly. 2020;150(0506):w20203. (doi: 10.4414/smw.2020.20203).

6. Guo YR, Cao QD, Hong ZS, et al. The origin, transmission and clinical therapies on coronavirus disease 2019 (COVID-19) outbreak - an update on the status. Mil Med Res. 2020;7(1):11. (doi: 10.1186/s40779-020-00240-0).

7. Petrosillo N, Viceconte G, Ergonul O, Ippolito G, Petersen E. COVID-19, SARS and MERS: are they closely related? Clin Microbiol Infect. 2020;26:729-34. (doi: 10.1016/j.cmi.2020.03.026).

8. Huang C, Wang Y, Li X, et al. Clinical features of patients infected with 2019 novel coronavirus in Wuhan, China. Lancet. 2020;395(10223):497-506. (doi: 10.1016/S0140-6736(20)30183-5).

9. Shi S, Qin M, Shen B. Association of cardiac injury with mortality in hospitalized patients with COVID-19 in Wuhan, China. JAMA Cardiol. 2020;5(7):802-10. (doi: 10.1001/jamacardio.2020.0950).

10. Inciardi RM, Lupi L, Zaccone G. Cardiac involvement in a patient with coronavirus disease 2019 (COVID-19). JAMA Cardiol. 2020;5(7):819-24. (doi: 10.1001/jamacardio.2020.1096).

11. Sala S, Peretto G, Gramegna M. Acute myocarditis presenting as a reverse Tako-Tsubo syndrome in a patient with SARS-CoV-2 respiratory infection. Eur Hear J. 2020;41(19):1861-2. (doi: 10.1093/eurheartj/ehaa286). 
12. Wang $\mathrm{D}, \mathrm{Hu} \mathrm{B}, \mathrm{Hu} \mathrm{C}$, et al. Clinical characteristics of 138 hospitalized patients with 2019 novel coronavirus-infected pneumonia in Wuhan, China. Jama. 2020;323(11):1061-9. (doi: 10.1001/jama.2020.1585).

13. Holshue ML, DeBolt C, Lindquist S, et al. First case of 2019 novel coronavirus in the United States. N Engl J Med. 2020;382:929-36. (doi: 10.1056/NEJMoa2001191).

14. Guan W, Ni Z, Hu Y, et al. Clinical characteristics of 2019 novel coronavirus infection in China. N Engl J Med 2020; 382:1708-20. (doi: 10.1056/NEJMoa2002032).

15. Chen Y, Chen L, Deng Q, et al. The Presence of SARS-CoV-2 RNA in Feces of COVID-19 Patients. J Med Virol. April 2020;92(7):83340. (doi: 10.1002/jmv.25825).

16. Pan L, Mu M, Yang P, et al. Clinical characteristics of COVID-19 patients with digestive symptoms in Hubei, China: a descriptive, cross-sectional, multicenter study. Am J Gastroenterol. 2020; 115(5):766-73. (doi: 10.14309/ajg.0000000000000620).

17. Cai Q, Huang D, Ou P, et al. COVID - 19 in a Designated Infectious Diseases Hospital Outside Hubei Province, China. Allergy. 2020;75(7):1742-52. (doi: 10.1111/all.14309).

18. Fan Z, Chen L, Li J, et al. Clinical Features of COVID-19-Related Liver Damage. Clin Gastroenterol Hepatol. 2020;18(7):1561-6. (doi: 10.1016/j.cgh.2020.04.002).

19. Mao L, Wang M, Chen S, et al. Neurological Manifestations of Hospitalized Patients with COVID-19 in Wuhan, China: A Retrospective Case Series Study. medRxiv. 2020. (doi: 10.2139/ssrn.3544840).

20. Li Z, Huang Y, Guo X. The brain, another potential target organ, needs early protection from SARS-CoV-2 neuroinvasion. Sci China Life Sci. 2020;2:2-4. (doi: 10.1007/s11427-020-1690-y).

21. Moriguchi T, Harii N, Goto J, et al. A first Case of Meningitis/Encephalitis associated with SARS-Coronavirus-2. Int J Infect Dis. 2020;94:55-8. (doi: 10.1016/j.ijid.2020.03.062).

22. Chen G, Wu D, Guo W. Clinical and immunological features of severe and moderate coronavirus disease 2019. J Clin Invest. 2020;130(5):2620-9. (doi: 10.1172/JCI137244).

23. Ruan Q, Yang K, Wang W, Jiang L, Song J. Clinical predictors of mortality due to COVID-19 based on an analysis of data of 150 patients from Wuhan, China. Intensive Care Med. 2020;46(5):8468. (doi: 10.1007/s00134-020-05991-x).

24. Zhou F, Yu T, Du R. Clinical course and risk factors for mortality of adult inpatients with COVID-19 in Wuhan, China: a retrospective cohort study. Lancet. 2020;395(10229):1054-62. (doi: 10.1016/S0140-6736(20)30566-3).
25. Wu C, Chen X, Cai Y. Risk factors associated with acute respiratory distress syndrome and death in patients with coronavirus disease 2019 pneumonia in Wuhan, China. JAMA Intern Med. 2020;180(7):934-43. (doi: 10.1001/jamainternmed.2020.0994).

26. Cheng Y, Luo R, Wang K. Kidney disease is associated with inhospital death of patients with COVID-19. Kidney Int. 2020;97(5):829-38. (doi: 10.1016/j.kint.2020.03.005).

27. Li Z, Wu M, Guo J. Caution on kidney dysfunctions of 2019-nCoV patients. medRxiv. 2020;2. (doi: 10.1101/2020.02.08.20021212).

28. Wang L, Li X, Chen H. Coronavirus disease 2019 infection does not result in acute kidney injury: an analysis of 116 hospitalized patients from Wuhan, China. Am J Nephrol. 2020;51(5):343-8. (doi: 10.1159/000507471).

29. Kim J, Thomsen T, Sell N, Goldsmith AJ. Abdominal and testicular pain: An atypical presentation of COVID-19. Am J Emerg Med. 2020;38(7):E1-3. (doi: 10.1016/j.ajem.2020.03.052).

30. World Health Organization. Report of the WHO-China Joint Mission on Coronavirus Disease 2019 (COVID-19). Geneva, Switzerland. 2002. https://www.who.int/docs/default-source/ coronaviruse/who-china-joint-mission-on-covid-19---finalreport-1100hr-28feb2020-11 mar-update.pdf?sfvrsn=1a13fda0_2\& download=true

31. Kim ES, Chin BS, Kang CK. Clinical course and outcomes of patients with severe acute respiratory syndrome coronavirus 2 infection: a preliminary report of the first 28 patients from the Korean cohort study on COVID-19. J Korean Med Sci. 2020;35(13):142. (doi: 10.3346/jkms.2020.35.e142).

32. Gane SB, Kelly C, Hopkins C. Isolated sudden onset anosmia in COVID-19 infection. A novel syndrome? Rhinology. 2020;58:1-4. (doi: 10.4193/Rhin20.114).

33. Chen L, Liu M, Zhang Z. Ocular manifestations of a hospitalised patient with confirmed 2019 novel coronavirus disease. Br J Ophthalmol. 2020;104(6):748-51. (doi: 10.1136/bjophthalmol2020-316304).

34. Lu C-W, Liu X-F, Jia Z-F. 2019-nCoV transmission through the ocular surface must not be ignored. Lancet. 2020;395:39. (doi: 10.1016/S0140-6736(20)30313-5).

35. Recalcati S. Cutaneous manifestations in COVID-19: a first perspective. J Eur Acad Dermatol Venereol. 2020;34(5):e212-e213. (doi: 10.1111/jdv.16387).

36. Zhang J, Dong X, Cao Y, et al. Clinical characteristics of 140 patients infected with SARS - CoV - 2 in Wuhan, China. Allergy. 2020;75(7):1730-41. (doi: 10.1111/all.14238). 
37. Mousavizadeh L, Ghasemi S. Genotype and phenotype of COVID19: Their roles in pathogenesis. J Microbiol Immunol Infect. 2020 March 31. (doi: 10.1016/j.jmii.2020.03.022).

38. Yin Y, Wunderink RG. MERS, SARS and other coronaviruses as causes of pneumonia. Respirology. 2018;23(2):130-7. (doi: 10.1111/resp.13196).

39. Su S, Wong G, Shi W, et al. Epidemiology, genetic recombination, and pathogenesis of coronaviruses. Trends Microbiol. 2016;24(6):490-502. (doi: 10.1016/j.tim.2016.03.003).

40. Guan W, Ni Z, Hu Y, et al. Clinical characteristics of coronavirus disease 2019 in China. N Engl J Med. 2020;382:1708-20. (doi: 10.1056/NEJMoa2002032).

41. Chen J. Pathogenicity and transmissibility of 2019-nCoV-a quick overview and comparison with other emerging viruses. Microbes Infect. 2020;22(2):69-71. (doi: 10.1016/j.micinf.2020.01.004).

42. Liu T, Hu J, Kang M, et al. Transmission dynamics of 2019 novel $\begin{array}{lll}\text { coronavirus } & (2019-\mathrm{nCoV}) . & \text { (doi: }\end{array}$ 10.1101/2020.01.25.919787)

43. Adhikari SP, Meng S, Wu YJ, et al. Epidemiology, causes, clinical manifestation and diagnosis, prevention and control of coronavirus disease (COVID-19) during the early outbreak period: A scoping review. Infect Dis Poverty. 2020;9(1):1-12. (doi: 10.1186/s40249020-00646-x)

44. Jin Y-H, Cai L, Cheng Z-S, et al. A rapid advice guideline for the diagnosis and treatment of 2019 novel coronavirus $(2019-\mathrm{nCoV})$ infected pneumonia (standard version). Mil Med Res. 2020;7(1):4.

45. Hui DS, I Azhar E, Madani TA, et al. The continuing 2019-nCoV epidemic threat of novel coronaviruses to global health - The latest 2019 novel coronavirus outbreak in Wuhan, China. Int J Infect Dis. 2020;91:264-6. (doi: 10.1016/j.ijid.2020.01.009).

46. Wu F, Zhao S, Yu B, et al. A new coronavirus associated with human respiratory disease in China. Nature. 2020;579(7798):265-9. (doi: 10.1038/s41586-020-2008-3).

47. Malik YS, Sircar S, Bhat S, et al. Emerging novel coronavirus (2019$\mathrm{nCoV}$-ccurrent scenario, evolutionary perspective based on genome analysis and recent developments. Vet Q. 2020;40(1):6876. (doi: 10.1080/01652176.2020.1727993).

48. Wu A, Peng Y, Huang B, et al. Genome composition and divergence of the novel coronavirus $(2019-\mathrm{nCoV})$ originating in China. Cell Host Microbe. 2020;27:325-8. (doi: 10.1016/j.chom.2020.02.001).

49. Zhang L, Shen F, Chen F, Lin Z. Origin and evolution of the 2019 novel coronavirus. Clin Infect Dis an Off Publ Infect Dis Soc Am. 2020;71(15):882-3. (doi: 10.1093/cid/ciaa112).
50. Tang $X, W u$ C, Li $X$, et al. On the origin and continuing evolution of SARS-CoV-2. Natl Sci Rev. March 2020;7(6):1012-23. (doi: $10.1093 / \mathrm{nsr} / \mathrm{nwaa036)}$.

51. de Wilde AH, Snijder EJ, Kikkert M, van Hemert MJ. Host factors in coronavirus replication. In: Roles of Host Gene and Non-Coding RNA Expression in Virus Infection. Springer; 2017;419:1-42. (doi: 10.1007/82_2017_25).

52. Sawicki SG, Sawicki DL. Coronavirus transcription: a perspective. In: Coronavirus Replication and Reverse Genetics. Springer; 2005:31-55. (doi: 10.1007/3-540-26765-4_2).

53. Hui DSC, Sung JJY. Severe acute respiratory syndrome. Chest. 2003;124(1):12-15. (doi: 10.1378/chest.124.1.12).

54. Wan Y, Shang J, Graham R, Baric RS, Li F. Receptor recognition by the novel coronavirus from Wuhan: an analysis based on decade-long structural studies of SARS coronavirus. J Virol. 2020;94(7): e00127-20. (doi: 10.1128/JVI.00127-20).

55. Frieman M, Heise M, Baric R. SARS coronavirus and innate immunity. Virus Res. 2008;133(1):101-12. (doi: 10.1016/j.virusres.2007.03.015).

56. Kawai T, Akira S. The role of pattern-recognition receptors in innate immunity: update on Toll-like receptors. Nat Immunol. 2010;11(5):373. (doi: 10.1038/ni.1863).

57. Chen C, Zhang XR, Ju ZY, He WF. Advances in the research of cytokine storm mechanism induced by Corona Virus Disease 2019 and the corresponding immunotherapies. Zhonghua shao shang za zhi= Zhonghua shaoshang zazhi= Chinese J Burn. 2020;36:E005.

58. Liu Q, Wang R, Qu G, Wang Y, Liu P, Zhu Y. General anatomy report of novel coronavirus pneumonia death corpse. J Forensic Med. 2020;36(1):19-21.

59. Sun J, He W-T, Wang L, et al. COVID-19: epidemiology, evolution, and cross-disciplinary perspectives. Trends Mol Med. 2020;26(5):483-95. (doi: 10.1016/j.molmed.2020.02.008).

60. Yang Y, Lu Q, Liu M, et al. Epidemiological and clinical features of the 2019 novel coronavirus outbreak in China. medRxiv. 2020. (doi: 10.1101/2020.02.10.20021675).

61. Pongpirul WA, Pongpirul K, Ratnarathon AC, Prasithsirikul W Journey of a Thai taxi driver and novel coronavirus. N Engl J Med. 2020;382(11):1067-8. (doi: 10.1056/NEJMc2001621).

62. Dong N, Cai J, Zhou Y, Liu J, Li F. End-stage Heart Failure with COVID-19: Strong Evidence of Myocardial Injury by 2019-nCoV. JACC Hear Fail. 2020;8(6):515-7. (doi: 10.1016/j.jchf.2020.04.001).

63. Akhmerov A, Marban E. COVID-19 and the Heart. Circ Res. 2020;126:1443-55. (doi: 10.1161/CIRCRESAHA.120.317055). 
64. Clerkin KJ, Fried JA, Raikhelkar J, et al. Coronavirus Disease 2019 (COVID-19) and Cardiovascular Disease. Circulation. 2020;141(20). (doi: 10.1161/CIRCULATIONAHA.120.046941).

65. Driggin E, Madhavan M V, B B. Cardiovascular Considerations for Patients, Health Care Workers, and Health Systems During the Coronavirus Disease 2019 (COVID-19) Pandemic. J Am Coll Cardiol. 2020;75(18):2352-71. (doi: 10.1016/j.jacc.2020.03.031).

66. Mishra AK, Sahu KK, Lal A, Sargent J. Patterns of heart injury in COVID-19 and relation to outcome. J Med Virol., First published: 8 April 2020. (doi: 10.1002/jmv.25847).

67. Mehta P, McAuley DF, Brown M, et al. COVID-19: consider cytokine storm syndromes and immunosuppression. Lancet. 2020;395(10229):1033-4. (doi: 10.1016/S0140-6736(20)30628-0).

68. Han H, Xie L, R L. Analysis of heart injury laboratory parameters in 273 COVID-19 patients in one hospital in Wuhan, China. J Med Virol. 2020;92(7):819-23. (doi: 10.1002/jmv.25809).

69. Chan JFW, Yuan S, Kok KH, et al. A familial cluster of pneumonia associated with the 2019 novel coronavirus indicating person-toperson transmission: a study of a family cluster. Lancet. 2020;395(10223):514-23. (doi: 10.1016/S0140-6736(20)30154-9).

70. Xu L, Liu J, Lu M, Yang D, Zheng X. Liver injury during highly pathogenic human coronavirus infections. Liver Int. 2020;40(5):998-1004. (doi: 10.1111/liv.14435).

71. Wong SH, Lui RN, Sung JJ. Covid-19 and the Digestive System. J Gastroenterol Hepatol. March 2020;35(5):744-8. (doi: 10.1111/jgh.15047).

72. Musa S. Hepatic and gastrointestinal involvement in coronavirus disease 2019 (COVID-19): What do we know till now? Arab J Gastroenterol. April 2020;21(1):3-8. (doi: 10.1016/j.ajg.2020.03.002).

73. Prompetchara E, Ketloy C, Palaga T. Immune responses in COVID19 and potential vaccines: Lessons learned from SARS and MERS epidemic. Asian Pacific J allergy Immunol. 2020;38(1):1-9. (doi: 10.12932/AP-200220-0772).

74. Lee I-C, Huo T-I, Huang Y-H. Gastrointestinal and liver manifestations in patients with COVID-19. J Chin Med Assoc. 2020;83(6):521-3. (doi: 10.1097/JCMA.0000000000000319).

75. Park SE. Epidemiology, virology, and clinical features of severe acute respiratory syndrome - coronavirus-2 (SARS-CoV-2; Coronavirus Disease-19). Clin Exp Pediatr. 2020 Apr; 63(4): 119124. (doi: 10.3345/cep.2020.00493).
76. Zhang T, Cui X, Zhao X, et al. Detectable SARS-CoV-2 Viral RNA in Feces of Three Children during Recovery Period of COVID-19 Pneumonia. J Med Virol. 2020;92(7):909-14. (doi: 10.1002/jmv.25795).

77. World Health Organization. Operational considerations for case management of COVID-19 in health facility and community:

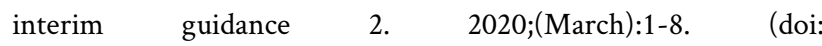
10.15557/PiMR.2020.0004).

78. Guo Y-R, Cao Q-D, Hong Z-S, et al. The origin, transmission and clinical therapies on coronavirus disease 2019 (COVID-19) outbreak - an update on the status. Mil Med Res. 2020;7(1):11. (doi: 10.1186/s40779-020-00240-0).

79. Baig AM, Khaleeq A, Ali U, Syeda H. Evidence of the COVID-19 Virus Targeting the CNS: Tissue Distribution, Host-Virus Interaction, and Proposed Neurotropic Mechanisms. ACS Chem Neurosci. 2020;11(7):995-8. (doi: 10.1021/acschemneuro.0c00122).

80. Wu Y, Xu X, Chen Z, et al. Nervous system involvement after infection with COVID-19 and other coronaviruses. Brain Behav Immun. 2020;87:18-22. (doi: 10.1016/j.bbi.2020.03.031).

81. Li YC, Bai WZ, Hashikawa T. The neuroinvasive potential of SARS-CoV2 may be at least partially responsible for the respiratory failure of COVID-19 patients. J Med Virol. 2020;2:0-2. (doi: 10.1002/jmv.25728).

82. Li Y, Bai W-Z, Hashikawa T. Response to Commentary on: "The neuroinvasive potential of SARS-CoV-2 may play a role in the respiratory failure of COVID-19 patients." J Med Virol. 2020;92(7):707-9. (doi: 10.1002/jmv.25824).

83. Zhou L, Zhang M, Wang J, Gao J. Sars-Cov-2: Underestimated damage to nervous system. Travel Med Infect Dis. 2020;(March):101642. (doi: 10.1016/j.tmaid.2020.101642).

84. Tan L, Wang Q, Zhang D. Lymphopenia predicts disease severity of COVID-19: a descriptive and predictive study. Signal Transduct Target Ther. 2020;5(1):1-3. (doi: 10.1038/s41392-020-0148-4).

85. Xu H, Zhong L, Deng J, et al. High expression of ACE2 receptor of 2019-nCoV on the epithelial cells of oral mucosa. Int J Oral Sci. 2020;12(8):1-5. (doi: 10.1038/s41368-020-0074-x).

86. Liao YC. IL-19 induces production of IL-6 and TNF-alpha and results in cell apoptosis through TNF-alpha. J Immunol. 2002;169(8):4288-97. (doi: 10.4049/jimmunol.169.8.4288).

87. Zhang L, Zhu F, Xie L. Clinical characteristics of COVID-19infected cancer patients: A retrospective case study in three hospitals within Wuhan, China. Ann Oncol. 2020;31(7):894-901. (doi: 10.1016/j.annonc.2020.03.296). 
88. Means Jr RT. Pathogenesis of the anemia of chronic disease: a cytokine-mediated anemia. Stem Cells. 1995;13(1):32-7. (doi: 10.1002/stem.5530130105).

89. Lippi G, Plebani M, Henry BM. Thrombocytopenia is associated with severe coronavirus disease 2019 (COVID-19) infections: A meta-analysis. Clin Chim Acta. 2020;506:145-8. (doi: 10.1016/j.cca.2020.03.022).

90. Xu D, Zhang H, Gong H, Chen J, Ye J, Meng T. Identification of a potential mechanism of acute kidney injury during the Covid-19 outbreak: A study based on single-cell transcriptome analysis. Intensive Care Med. 2020;46(6):1114-6. (doi: 10.1007/s00134-02006026-1).

91. Fan C, Li K, Ding Y, Lu W, Wang J. ACE2 expression in kidney and testis may cause kidney and testis damage after 2019-nCoV infection. medRxiv. 2020. (doi: 10.1101/2020.02.12.20022418).

92. Xu J, Qi L, Chi X. Orchitis: a complication of severe acute respiratory syndrome (SARS). Biol Reprod. 2006;74(2):410-6. (doi: 10.1095/biolreprod.105.044776).

93. Huo N, Lu H, Xu X, et al. The clinical characteristics and outcome of 45 early stage patients with SARS. Beijing Da Xue Xue Bao Yi Xue Ban. 2003;35:19-22.

94. Joob B, Wiwanitkit V. Arthralgia as an initial presentation of COVID-19: observation. Rheumatol Int. 2020;40(5):823. (doi: 10.1007/s00296-020-04561-0)

95. Griffith JF. Musculoskeletal complications of severe acute respiratory syndrome. Semin Musculoskelet Radiol. 2011;15(5):554-60. (doi: 10.1055/s-0031-1293500).

96. Pongratz D, Fischer P, Späth M. Pathophysiology of Inflammatory Muscle Pain. J Musculoskelet Pain. 2002;10(1-2):121-9. (doi: 10.1300/J094v10n01_10).

97. Wujtewicz M, Dylczyk-Sommer A, Aszkiełowicz A, Zdanowski S, Piwowarczyk S, Owczuk R. COVID-19 - what should anaethesiologists and intensivists know about it? Anaesthesiol Intensive Ther. 2020;52(1):34-41. (doi: 10.5114/ait.2020.93756).
98. Soler ZM, Patel ZM, Turner JH, Holbrook EH. A primer on viralassociated olfactory loss in the era of COVID-19. Int Forum Allergy Rhinol. 2020;10(7):814-20. (doi: 10.1002/alr.22578).

99. Cavazzana A, Larsson M, Munch M, Hahner A, Hummel T. Postinfectious olfactory loss: A retrospective study on 791 patients. Laryngoscope. 2018;128(1):10-5. (doi: 10.1002/lary.26606).

100.Aung K. Viral pharyngitis clinical presentation. Medscape. Medscape. 2019. Available at: https://emedicine.medscape.com/ article/225362-clinical\#b4 (Accessed: 15 April 2020).

101. Worrall G. Acute sore throat. Can Fam Physician. 2007;57(11):1961.

102.Choudhary R, Kapoor MS, A S, Bodakhe SH. Therapeutic targets of renin-angiotensin system in ocular disorders. J Curr Ophthalmol. 2017;29(1):7-16. (doi: 10.1016/j.joco.2016.09.009).

103.Sun Y, Liu L, Pan X, Jing M. Mechanism of the action between the SARS-CoV S240 protein and the ACE2 receptor in eyes. J Virol. 2006;6(4):783-6.

104.Joob B, Wiwanitkit V. COVID-19 can present with a rash and be mistaken for Dengue. J Am Acad Dermatol. 2020;82(5):e177. (doi: 10.1016/j.jaad.2020.03.036).

105. Wang M, Cao R, Zhang L, et al. Remdesivir and chloroquine effectively inhibit the recently emerged novel coronavirus (2019$\mathrm{nCoV}$ ) in vitro. Cell Res. 2020;30(3):269-71. (doi: 10.1038/s41422020-0282-0)

106.Lim J, Jeon S, Shin H-Y, et al. Case of the index patient who caused tertiary transmission of COVID-19 infection in Korea: the application of lopinavir/ritonavir for the treatment of COVID-19 infected pneumonia monitored by quantitative RT-PCR. J Korean Med Sci. 2020;35(6):e79. (doi: 10.3346/jkms.2020.35.e88).

107. Qin C, Zhou L, Hu Z, et al. Dysregulation of immune response in patients with COVID-19 in Wuhan, China. Clin Infect Dis. 2020;71(15):762-8. (doi: 10.1093/cid/ciaa248). 